Jurnal Ekonomi \& Studi Pembangunan

Volume 18, Nomor 2, Oktober 2017, hlm. 173-182

DOI: 10.18196/jesp.18.2.4048

\title{
STRATEGI PENGEMBANGAN KOTA MAGELANG SEBAGAI KAWASAN ANDALAN DI PROVINSI JAWA TENGAH
}

\author{
Rica Ayu Nuraini, Lilies Setiartiti \\ Pogram Studi Ilmu Ekonomi, Fakultas Ekonomi dan Bisnis \\ Universitas Muhammadiyah Yogyakarta \\ Email Korespondensi: richaayun@gmail.com
}

Naskah Diterima: Agustus 2017; Disetujui: Oktober 2017

\begin{abstract}
This research aims to determine the classification of economics structure and the leading sectors of Magelang. The analysis of the research employs Klassen's Tipology, Location Quotient and SWOT. The results show that the city of Magelang is included in the advanced and fastgrowing regions with high economic growth and high per capita income. Location Quotient (LQ) shows all secondary and tertiary sectors are included in the leading sectors, while agricultural sector, mining sector and manufacturing sector are not included in the leading sector. Based on SWOT analysis, there are leading sectors that needs to be improved to persuade the better economic condition in the main area of Magelang city, by taking action some possible development strategies, such as, improving the base sector's products by utilizing advanced technology, maximizing the realization of investment and maximizing the sale of leading sector products as well as creative industry products. Another possible startegies are creating a conducive business environment and improving the competitiveness of the regional economy.
\end{abstract}

Keywords: GRDP, Klassen Typology, Location Quotient, SWOT

JEL Classification: E01, R58, H70

\begin{abstract}
Abstrak: Penelitian ini bertujuan untuk mengetahui klasifikasi struktur ekonomi dan sektor unggulan kota Magelang. Model analisis yang digunakan adalah analisis Tipologi Klassen, Location Quotient dan SWOT. Hasil penelitian menunjukkan bahwa kota Magelang termasuk dalam klasifikasi daerah maju dan berkembang cepat dengan pertumbuhan ekonomi dan pendapatan per kapita yang tinggi. Location Quotient (LQ) menunjukkan semua sektor sekunder dan tersier merupakan sektor unggulan kota Magelang, sedangkan sektor pertanian, sektor pertambangan dan sektor manufaktur tidak termasuk sektor unggulan kota Magelang. Berdasarkan hasil analisis SWOT, strategi pengembangan bagi kawasan utama yang perlu dilakukan adalah dengan memperbaiki posisi ekonomi kota Magelang, yaitu dengan mengembangkan produk sektor dasar dengan memanfaatkan kemajuan teknologi, memaksimalkan realisasi investasi dan memaksimalkan penjualan baik produk sektor unggulan maupun produk industri kreatif. Strategi berikutnya adalah menciptakan iklim usaha yang kondusif dan meningkatkan daya saing perekonomian daerah.
\end{abstract}

Kata kunci: PDRB, Tipologi Klassen, Location Quotient, SWOT

Klasifikasi JEL: E01, R58, H70 


\section{PENDAHULUAN}

Menurut Arsyad dalam Sabana (2007) pembangunan daerah dalam perspektif ekonomi merupakan sebuah proses dikelolanya sumber daya ekonomi yang berada di suatu daerah oleh pemerintah setempat beserta dengan masyarakat membangun pola kerjasama untuk mencapai tujuan terciptanya lapangan kerja baru, meluasnya kesempatan kerja serta terangsangnya iklim ekonomi di wilayah tersebut.

Pemerintah melalui UU No. 32 Tahun 2004 tentang "Pemerintah Daerah" dan UU No. 23 Tahun 2004 tentang "Perimbangan Keuangan antara Pemerintah Pusat dan Daerah" yang membahas tentang kebijakan pemerintah pusat dalam melimpahkan wewenang untuk mengatur urusan rumah tangga daerahnya sendiri kepada pemerintah daerah melalui perencanaan dan pengelolaan pembangunan daerah yang didasarkan pada kemampuan ataupun potensi yang ada serta permasalahan yang harus dihadapi di daerah tersebut.

Pelimpahan wewenang yang dilakukan oleh pemerintah pusat kepada daerah diharapkan dapat menghilangkan praktik sentralistik dimana pembangunan dan pertumbuhan ekonomi hanya terpusat di kota besar saja, yang pada satu sisi dirasa kurang menguntungkan daerah dan penduduk lokal. Dalam rangka melakukan pemerataan pembangunan daerah di segala penjuru negeri, era otonomi daerah merupakan hal yang paling penting, karena dirasa dapat meningkatkan motivasi daerah untuk mau mengembangkan diri menjadi daerah yang maju dengan tingkat kesejahteraan yang meningkat dan dapat bersaing dengan daerah lain. Selain itu, untuk pengaktualisasian pribadi daerah dengan pertumbuhan ekonomi yang tinggi yang dapat diwujudkan dengan pemanfaatan potensi local serta dilakukannya pemanfaatan kekuatan daerah dan peluang yang muncul untuk mengembangkan berbagai kegiatan-kegiatan perekonomian untuk mencapai kemakmuran rakyat dan keadilan sosial.

Berlakunya kebijakan pembangunan daerah dengan konsep kawasan andalan oleh pemerintah bertujuan untuk mempersempit jurang disparitas antar daerah yang kemudian disandarkan pada kekuatan lokal yang dimiliki. Kebijakan kawasan andalan diterapkan dengan harapan dapat terwujudnya kesamarataan tingkat pertumbuhan ekonomi serta keseimbangan pendapatan perkapita daerah, sehingga dapat memperkecil bahkan menutupi kesenjangan ekonomi yang ada antara perkembangan pulau jawa maupun luar jawa (Kuncoro, 2002).

Menurut Rencana Tata Ruang Wilayah (RTRW) Provinsi Jateng 2003 dalam Sabana (2007) mendefinisikan Kawasan Andalan merupakan kawasan yang ditetapkan dengan tujuan untuk dibudidayakan berdasarkan potensi lokal yang dimiliki yang diyakini dapat merangsang iklim ekonomi yang baik, yang dapat ditinjau dari peningkatan pertumbuhan ekonomi tidak hanya untuk kawasan itu sendiri namun juga bagi kawasan sekitarnya.

Konsep Kawasan Andalan menurut Royat dalam Kuncoro (2002) merupakan kawasan cepat tumbuh dan maju diantara daerah lainnya dalam satu provinsi, kawasan andalan juga diyakini memiliki sektor unggulan yang telah terspesialisasikan, yang dapat berperan sebagai penggerak perekonomian daerah serta memiliki kaitan dengan daerah di sekitarnya. Terjadinya pertumbuhan ekonomi di kawasan andalan diyakini dapat memberi imbas positif tidak hanya untuk daerah tersebut, namun juga daerah sekitarnya dengan diberdayakannya sektor serta subsektor unggulan yang dapat menjadi mesin penggerak perekonomian daerah. Penekanan pada pertumbuhan ekonomi sebagai arah kebijakan penetapan Kawasan Andalan dikarenakan pertumbuhan ekonomi merupakan 
variabel ekonomi yang merupakan indikator inti dalam pembangunan.

Tingkat kinerja perekonomian wilayah dapat diperhatikan melalui besaran PDRB dan pertumbuhan PDRBnya, sementara tingkat kesejahteraan masyarakat di suatu wilayah dapat dilihat dari PDRB perkapita. Berikut pada tabel 1 menunjukkan laju pertumbuhan PDRB dan PDRB perkapita kabupaten/kota di Karesidenan Kedu. Untuk dapat memperjelas kondisi pertumbuhan PDRB Kota Magelang pada tahun 2010-2014 dibandingkan dengan pertumbuhan PDRB Jawa Tengah dijelaskan dalam Gambar 1

Tabel 1. Pertumbuhan PDRB Atas Dasar Harga Konstan Tahun 2010 Karesidenan Kedu Periode 2010 - 2014 (dalam \%)

\begin{tabular}{lllllllr}
\hline No. & Kabupaten/Kota & $\mathbf{2 0 1 0}$ & $\mathbf{2 0 1 1}$ & $\mathbf{2 0 1 2}$ & $\mathbf{2 0 1 3}$ & $\mathbf{2 0 1 4}$ & Rata-rata \\
\hline 1 & Kabupaten Purworejo & 4,84 & 5,64 & 4,59 & 4,94 & 4,49 & 4,90 \\
\hline 2 & Kabupaten Wonosobo & 4,29 & 4,52 & 5,14 & 5,25 & 4,16 & 4,67 \\
\hline 3 & Kabupaten Magelang & 4,51 & 5,22 & 4,88 & 5,91 & 4,88 & 5,08 \\
\hline 4 & Kota Magelang & 6,12 & 6,11 & 5,37 & 6,04 & 4,90 & 5,71 \\
\hline 5 & Jawa Tengah & 5,84 & 5,30 & 5,34 & 5,11 & 5,28 & 5,37 \\
\hline Sumber: & BPS Kota Magelang dan Jawa Tengah diolah
\end{tabular}

Sumber: BPS Kota Magelang dan Jawa Tengah diolah

\section{Laju Pertumbuhan PDRB Kota Magelang dan Jawa Tengah}

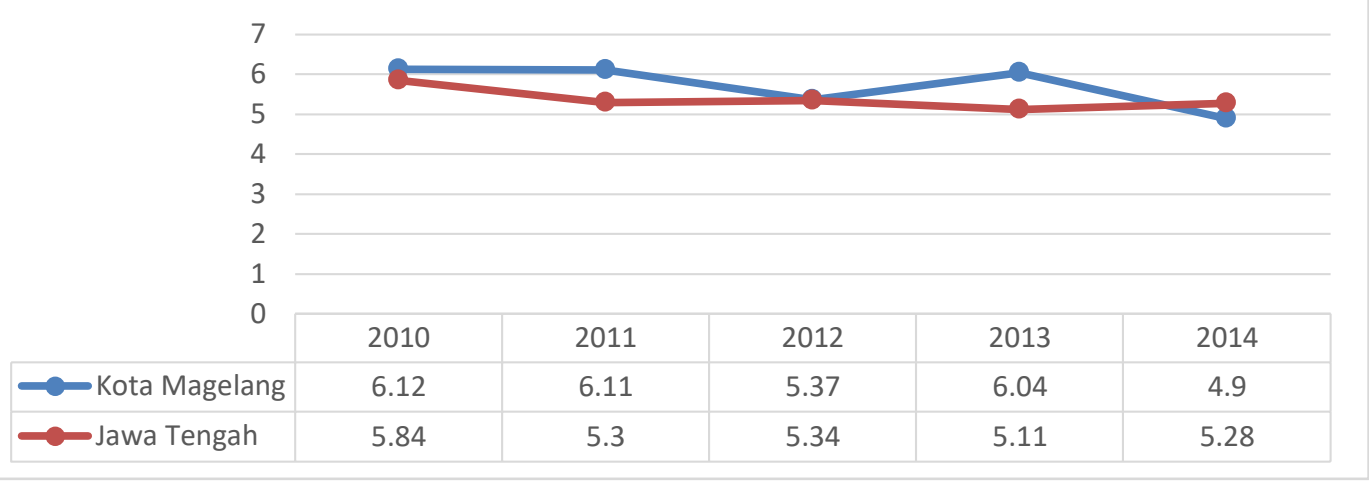

Sumber: BPS Provinsi Jawa Tengah dan Kota Magelang (data diolah)

Gambar 1. Pertumbuhan PDRB Kota Magelang dan Provinsi Jawa Tengah ADHK 2010 Periode 2010 - 2014

Rata - rata laju pertumbuhan PDRB Kota Magelang (5,71) lebih besar dari laju pertumbuhan PDRB Jawa tengah $(5,37)$ antara tahun 2010 -2014, walaupun rata-rata laju pertumbuhan PDRB Kota Magelang lebih besar dari Jawa Tengah, namun jika diperhatikan menurut runtut tahun pertumbuhan PDRB Kota Magelang fluktuatif. Pertumbuhan ekonomi Kota Magelang mengalami penurunan setelah tahun 2010, namun sampai dengan tahun 2013 laju pertumbuhan ekonomi Kota Magelang lebih besar dibandingkan dengan pertumbuhan ekonomi Provinsi Jawa Tengah. Pada tahun 2014 pertumbuhan ekonomi Kota Magelang justru mengalami penurunan yang cukup signifikan sehingga menempatkan pertumbuhan ekonomi Kota Magelang lebih kecil dari pertumbuhan ekonomi Provinsi Jawa Tengah. Berbeda hal nya dengan rata-rata pendapatan perkapita Kota Magelang lebih besar dari pendapatan perkapita 
Jawa Tengah dalam kurun waktu 2010-2014. Mengingat Kota Magelang merupakan pusat pertumbuhan di wilayah kerjasamanya sehingga dianggap dapat memiliki daya tarik investasi yang baik serta memiliki prospek ekonomi yang berkelanjutan.

\section{METODE PENELITIAN}

\section{Objek Penelitian}

Penelitian ini dilakukan di Kota Magelang yang merupakan salah satu kota yang ditetapkan menjadi kawasan andalan wilayah jawa tengah pada Perda Jawa Tengah No. 6 tahun 2010 mengenai Rencana Tata Ruang Wilayah (RTRW) Jawa Tengah Periode Tahun 2009 - 2029. Kota Magelang merupakan daerah yang ditetapkan sebagai objek penelitian karena potensi yang dimiliki serta kemampuan daerah untuk menjadi kawasan andalan.

\section{Jenis Data}

Data yang digunakan dalam penelitian ini adalah data sekunder berupa time series. Data sekunder adalah data-data pendukung yang didapat dari buku-buku, jurnal-jurnal, artikel, majalah, dan sebagainya yang memiliki relevansi dengan penelitian atau dengan mengambil dari sumber lain yang dipublikasikan oleh lembaga yang dianggap kompeten berupa data PDRB Kota Magelang dan Provinsi Jawa Tengah dalam periode tahun 2010-2014.

\section{Sumber Data}

Sumber data dalam penelitian ini adalah berbagai macam sumber yang diperoleh melalui data sekunder yang berasal dari BPS Kota Magelang, BPS Provinsi Jawa Tengah, Badan Perencanaan Pembangunan Daerah dan sumber lain seperti internet dan studi kepustakaan. Obyek penelitian ini adalah Kota Magelang dengan menggunakan data Produk Domestik
Regional Bruto (PDRB) atas dasar harga konstan tahun 2010 dari tahun 2010-2014. Data yang digunakan terbatas pada tujuh belas sektor yang ada dalam komponen PDRB dengan kemudian melakukan perbandingan terhadap PDRB di tingkat Provinsi Jawa Tengah atas dasar harga konstan 2010 dari tahun 2010-2014.

\section{Teknik Pengumpulan Data}

Metode dokumentasi merupakan suatu teknik dalam memperoleh serta mengumpulkan data atau informasi mengenai berbagai hal yang memiliki kaitan dengan penelitian, dengan cara memeriksa kembali laporan-laporan tertulis baik berupa angka maupun keterangan.

\section{Metode Analisis Data}

\section{Analisis Tipologi Klassen}

Analisis Tipologi Klassen ini dimanfaatkan untuk dapat mengetahui pola serta struktur pertumbuhan ekonomi dari masing-masing daerah. Menurut tipologi daerah, daerah dibagi menjadi 4 klasifikasi, atau empat kuadran, yaitu:

Daerah cepat maju atau tumbuh cepat merupakan daerah dengan laju pertumbuhan ekonomi daerah serta pendapatan perkapita yang lebih besar dari pada rata-rata regional

Daerah maju tertekan merupakan daerah dengan pendapatan perkapita yang lebih besar dari pendapatan perkapita provinsi, namun memiliki tingkat pertumbuhan ekonomi yang lebih kecil dari rata-rata pertumbuhan ekonomi di tingkat regional atau provinsi.

Daerah cepat berkembang merupakan daerah dengan pertumbuhan ekonomi lebih besar, namun pendapatan perkapita lebih kecil dari rata-rata pendapatan perkapita regional.

Daerah relatif tertinggal merupakan daerah dengan kedua indikator yaitu pertumbuhan ekonomi dan pendapatan perkapita lebih kecil dari rata-rata regional. 
Tabel 2. Klasifikasi Pertumbuhan Ekonomi Tipologi Klassen

\begin{tabular}{|c|l|l|}
\hline \multicolumn{1}{r|}{$\mathrm{y}$} & \multicolumn{1}{|c|}{ yi $>\mathrm{r}$} & \multicolumn{1}{c|}{$\mathrm{yi}<\mathrm{r}$} \\
\hline $\mathrm{ri}>\mathrm{r}$ & Daerah maju atau tumbuh cepat & Daerah cepat berkembang \\
\hline $\mathrm{ri}<\mathrm{r}$ & Daerah maju tertekan & Daerah relatif tertinggal \\
\hline \multicolumn{2}{|c}{ Sumber: Syafrizal, 1997 }
\end{tabular}

Keterangan:

ri : laju pertumbuhan PDRB daerah studi

$r$ : laju pertumbuhan PDRB regional

yi : pendapatan perkapita daerah studi

y : pendapatan perkapitan regional.

\section{Analisis Location Quotient (LQ)}

Analisis LQ merupakan alat analisis yang berguna untuk mengidentifikasi basis ekonomi suatu wilayah terutama dari kriteria kontribusi. Analisis ini dapat mengetahui besaran tingkat spesialisasi basis ekonomi atau unggulan di suatu daerah.

$$
\mathrm{LQ}=\frac{\mathrm{Xi} / \mathrm{Xt}}{\mathrm{Yi} / \mathrm{Yt}}
$$

Keterangan:

LQ: Koefisien Location Quotient

Xi: Output sektor i daerah studi

(Kota/Kabupaten)

Xt : Output total daerah studi (Kota/Kabupaten)

Yi: Output sektor i daerah referensi

(regional/nasional)

Yt: Output total daerah referensi

(regional/nasional)
Rumus diatas menghasilkan tiga kriteria perhitungan Location Quotient (LQ) dalam perekonomian daerah yaitu:

Jika nilai LQ>1, maka sektor yang bersangkutan di daerah studi lebih terspesialisasi dibandingkan dengan daerah referensi. Artinya, sektor tersebut dalam perekonomian daerah di wilayah studi mempunyai keunggulan komparatif dan dapat dikategorikan sebagai sektor basis.

Jika nilai $L Q<1$, maka sektor yang bersangkutan di daerah studi kurang terspesialisasi dibandingkan dengan daerah referensi. Sektor tersebut dikategorikan sebagai sektor non-basis.

Jika nilai $L Q=1$, maka sektor yang bersangkutan di daerah studi dan daerah referensi memiliki peningkatan yang sama.

\section{Analisis SWOT}

Menurut Perce dan Robinson dalam Muhammad Ghufron (2008) analisis SWOT dapat digunakan untuk mengidentifikasi dan juga menyelaraskan indikator-indikator yang berasal dari internal maupun eksternal lingkungan secara sistematis, dan dapat berperan sebagai katalisator dalam proses pembuatan perencanaan pembangunan

Tabel 3. Analysis SWOT

\begin{tabular}{|c|c|c|}
\hline Eksternal & $\begin{array}{c}\text { STRENGTH (S) } \\
\text { Daftar Kekuatan Internal }\end{array}$ & $\begin{array}{c}\text { WEAKNESS (W) } \\
\text { Daftar Kelemahan Internal }\end{array}$ \\
\hline $\begin{array}{c}\text { OPPORTUNITIES } \\
\text { (O) } \\
\text { Daftar Peluang } \\
\text { Eksternal }\end{array}$ & $\begin{array}{c}\text { STRATEGIS SO } \\
\text { Gunakan kekuatan untuk } \\
\text { memanfaatkan peluang }\end{array}$ & $\begin{array}{c}\text { STRATEGI WO } \\
\text { Memanfaatkan peluang yang } \\
\text { muncul untuk mengatasi kelemahan }\end{array}$ \\
\hline $\begin{array}{c}\text { THREATS (T) } \\
\text { Daftar Ancaman } \\
\text { Ekstenal }\end{array}$ & $\begin{array}{c}\text { STRATEGIS ST } \\
\text { Gunakan kekuatan untuk menghindari } \\
\text { ancaman }\end{array}$ & $\begin{array}{c}\text { STRATEGI WT } \\
\text { Memerkecil kelemahan dan } \\
\text { menghindari ancaman }\end{array}$ \\
\hline
\end{tabular}

Strategi Pengembangan Kota Magelang... (Rica Ayu Nuraini, Lilies Setiartiti) 


\section{HASIL DAN PEMBAHASAN}

\section{Analisis Tipologi Klassen}

Adapun untuk mengetahui hasil dari klasifikasi Tipologi Klassen dapat dilihat dari ratarata laju pertumbuhan PDRB dan rata-rata pendapatan perkapita daerah Kota Magelang dan
Provinsi Jawa Tengah pada Tabel 4. Dari Tabel 4. Dapat dilihat bahwa Kota Magelang termasuk dalam klasifikasi daerah yang cepat tumbuh dan memiliki pendapatan per kapita yang cukup tinggi.

Tabel 4. Laju PDRB dan Perkapita Kota Magelang dan Jawa Tengah 2010-2015

\begin{tabular}{|c|c|c|c|c|}
\hline \multicolumn{5}{|c|}{ Kota Magelang } \\
\hline No & Tahun & Pertumbuhan (\%) & Pendapatan Perkapita (Rp) & Keterangan \\
\hline 1 & 2010 & 6,12 & 3.392.388 & Daerah cepat tumbuh \\
\hline 2 & 2011 & 6,11 & 3.588 .066 & Daerah cepat tumbuh \\
\hline 3 & 2012 & 5,37 & 3.723 .022 & Daerah cepat tumbuh \\
\hline 4 & 2013 & 6,04 & 3.964 .724 & Daerah cepat tumbuh \\
\hline 5 & 2014 & 4,90 & 4.143 .936 & Daerah maju tertekan \\
\hline 6 & 2015 & 5,07 & 4.338 .797 & Daerah maju tertekan \\
\hline & Rata-rata & 5,60 & 3.858 .488 & Daerah cepat tumbuh \\
\hline \multicolumn{5}{|c|}{ Jawa Tengah } \\
\hline No & Tahun & Pertumbuhan (\%) & \multicolumn{2}{|l|}{ Pendapatan Perkapita (Rp) } \\
\hline 1 & 2010 & 5,84 & \multicolumn{2}{|l|}{1.924 .563} \\
\hline 2 & 2011 & 5,30 & \multicolumn{2}{|l|}{2.010 .403} \\
\hline 3 & 2012 & 5,34 & \multicolumn{2}{|l|}{2.077 .965} \\
\hline 4 & 2013 & 5,11 & \multicolumn{2}{|l|}{2.184 .487} \\
\hline 5 & 2014 & 5,28 & \multicolumn{2}{|l|}{2.282 .016} \\
\hline 6 & 2015 & 5,44 & \multicolumn{2}{|l|}{2.388 .244} \\
\hline & Rata-rata & 5,39 & \multicolumn{2}{|l|}{2.144 .613} \\
\hline
\end{tabular}

Sumber: BPS Kota Magelang diolah

Dari hasil perhitungan yang dapat dilihat dari tabel 4 menunjukkan bahwa keadaan perekonomian Kota Magelang bergerak fluktuatif dari tahun ke tahunnya. Pada tahun 2010 Magelang unggul daripada Jawa Tengah dengan laju pertumbuhan PDRB sebesar 6,12\%, kemudian mengalami penurunan pada tahun 2011 sebesar 6,11\%. Tahun 2012 pertumbuhan PDRB Magelang mengalami penurunan yang dapat dikatakan cukup signifikan dengan persentase sebesar 5,37\%, namun pertumbuhan PDRB Kota Magelang tetap lebih besar dari pertumbuhan PDRB Jawa Tengah. Tahun 2013 Magelang tetap berada pada posisi melebihi Jawa Tengah dengan laju pertumbuhan 6,04\% sedangkan Jawa Tengah sebesar 5,11\%. Keterpurukan pertumbuhan perekonomian Kota Magelang terjadi pada tahun 2014 dan berkelanjutan hingga tahun 2015 yang menempatkan laju pertumbuhan PDRB Kota Magelang lebih kecil dari Jawa Tengah yaitu sebesar $4,90 \%$ pada tahun 2014 dan 5,07\% di tahun 2015. Rata-rata laju pertumbuhan Kota Magelang dan Jawa Tengah terhitung pada tahun 2010-2015, Kota Magelang memiliki rata-rata sebesar $5,60 \%$ yang lebih unggul $0,21 \%$ dari Jawa Tengah yaitu 5,39\%. Perhitungan pendapatan perkapita Kota Magelang menunjukkan bahwa posisi Kota Magelang berada diatas Jawa Tengah, 
dengan pendapatan perkapita $\operatorname{Rp} \quad 3.858 .488$ Tengah sebesar Rp 2.114.613.

dimiliki oleh Kota Magelang sementara Jawa

Analisis Location Quotient

Tabel 5. Hasil Analisis Location Quotient

\begin{tabular}{|c|c|c|c|c|c|c|c|}
\hline \multirow{2}{*}{ Sektor } & \multicolumn{6}{|c|}{ Location Quotient } & \multirow{2}{*}{$\begin{array}{l}\text { Rata-rata } \\
\text { LQ }\end{array}$} \\
\hline & 2010 & 2011 & 2012 & 2013 & 2014 & 2015 & \\
\hline Pertanian, Kehutanan dan Perikanan & 0.1457 & 0.1448 & 0.1432 & 0.1442 & 0.1479 & 0.1428 & 0.1448 \\
\hline Pertambangan dan Penggalian & 0.0000 & 0.0000 & 0.0000 & 0.0000 & 0.0000 & 0.0000 & 0.0000 \\
\hline Industri Pengolahan & 0.4081 & 0.4228 & 0.4250 & 0.4313 & 0.4334 & 0.4364 & 0.4262 \\
\hline Pengadaan Listrik dan Gas & 2.9496 & 3.1169 & 3.2908 & 3.4019 & 3.3860 & 3.4135 & 3.2598 \\
\hline $\begin{array}{l}\text { Pengadaan Air, Pengelolaan Sampah, } \\
\text { Limbah, dan Daur Ulang }\end{array}$ & 2.0492 & 2.0514 & 2.0725 & 2.0788 & 2.0642 & 2.0711 & 2.0645 \\
\hline Konstruksi & 1.7667 & 1.7451 & 1.7559 & 1.7310 & 1.6935 & 1.6642 & 1.7261 \\
\hline $\begin{array}{l}\text { Perdagangan Besar dan Eceran; Reparasi } \\
\text { Mobil dan Sepeda Motor }\end{array}$ & 1.1166 & 1.1231 & 1.1237 & 1.1276 & 1.1104 & 1.1014 & 1.1171 \\
\hline Transportasi dan Pergudangan & 2.3676 & 2.3500 & 2.3328 & 2.3515 & 2.3383 & 2.3197 & 2.3433 \\
\hline $\begin{array}{l}\text { Penyediaan Akomodasi dan Makan } \\
\text { Minum }\end{array}$ & 1.9111 & 1.9214 & 1.8769 & 1.8799 & 1.8623 & 1.8526 & 1.8840 \\
\hline Informasi dan Komunikasi & 1.4502 & 1.4688 & 1.4775 & 1.4898 & 1.5347 & 1.5159 & 1.4895 \\
\hline Jasa Keuangan dan Asuransi & 1.8040 & 1.8047 & 1.7925 & 1.8034 & 1.7716 & 1.7298 & 1.7844 \\
\hline Real Estate & 2.0226 & 2.0356 & 2.0097 & 2.0200 & 1.9783 & 1.9495 & 2.0026 \\
\hline Jasa Perusahaan & 1.0551 & 1.0472 & 1.0583 & 1.0100 & 1.0013 & 0.9859 & 1.0263 \\
\hline $\begin{array}{l}\text { Adminstrasi Pemerintahan, Pertahanan } \\
\text { dan Jaminan Sosial Wajib }\end{array}$ & 4.1533 & 4.1443 & 4.1715 & 4.1721 & 4.1188 & 4.0745 & 4.1391 \\
\hline Jasa Pendidikan & 1.6603 & 1.6991 & 1.7166 & 0.1842 & 1.7804 & 1.7747 & 1.4692 \\
\hline Jasa Kesehatan dan Kegiatan Sosial & 3.4125 & 3.4344 & 3.4051 & 3.3318 & 3.2528 & 3.2355 & 3.3453 \\
\hline Jasa Lainnya & 1.4129 & 1.4165 & 1.4000 & 1.4089 & 1.3641 & 1.3599 & 1.3937 \\
\hline
\end{tabular}

Sumber: BPS Kota Magelang diolah

Berdasarkan hasil perhitungan LQ pada tabel 5 diatas, dapat diketahui bahwa dari 17 total jumlah sektor yang ada kecuali sektor pertambangan, hanya ada dua sektor saja yang memiliki nilai $\mathrm{LQ}<1$ yaitu sektor pertanian, kehutanan dan perikanan serta sektor industri pengolahan dengan nilai rata-rata LQ sebesar 0,1448 untuk sektor pertanian, kehutanan dan perikanan dan 0,4262 untuk sektor industri pengolahan. Artinya, bahwa sektor pertanian, kehutanan dan perikanan serta sektor industri pengolahan bukan termasuk sektor basis dan dinilai kurang potensial untuk dapat dikembangkan sehingga dapat menggerakkan perekonomian Kota Magelang. Kota Magelang sebagai kota kecil yang berada di tengah Kabupaten Magelang tidak memiliki lahan pertanian, kehutanan dan perikanan yang cukup luas untuk dapat memberikan sumbangan yang besar terhadap pertumbuhan ekonomi.

Perhitungan LQ yang dilakukan selama periode pengamatan menunjukkan terdapat beberapa sektor yang memiliki nilai $L Q>1$, yaitu sektor pengadaan listrik dan gas, sektor pengadaan air, pengolahan sampah, limbah dan daur ulang, sektor konstruksi, sektor perdagangan besar dan eceran; reparasi mobil dan sepeda, sektor transportasi dan pergudangan, sektor penyediaan akomodasi dan makan/minum, sektor informasi dan komunikasi, sektor jasa keuangan dan asuransi, sektor real estate, sektor jasa perusahaan, sektor administrasi pemerintah,pertahanan dan jaminan sosial waib, sektor jasa pendidikan, sektor jasa 
kesehatan dan kegiatan serta sektor jasa lainnya. Sektor-sektor tersebut merupakan sektor basis yang juga merupakan sektor unggulan Kota Magelang yang ditunjukkan dengan LQ>1.

\section{Analisis SWOT}

Hasil analisis SWOT dapat dilihat pada

Tabel 6.

\section{Tabel 6. Hasil Analisis SWOT}

\begin{tabular}{|c|c|c|}
\hline & $\begin{array}{l}\text { STRENGTH (S) } \\
\text { 1. Kota Magelang termasuk dalam } \\
\text { kategori daerah cepat tumbuh dan } \\
\text { cepat maju } \\
\text { 2. Pendapatan perkapita tinggi } \\
\text { 3. Rata-rata pertumbuhan ekonomi } \\
\text { tahun 201-2015 lebih besar dari Jawa } \\
\text { Tengah } \\
\text { 4. Memiliki } 14 \text { sektor basis dengan } \\
\text { nilai LQ>1 } \\
\text { 5. Daya saing tinggi }\end{array}$ & $\begin{array}{l}\text { WEAKNESS }(\mathbf{W}) \\
\text { 1. Investasi yang belum maksimal } \\
\text { 2. Pertumbuhan sektor industri } \\
\text { pengolahan yang rendah } \\
\text { 3. Promosi sektor unggulan dan } \\
\text { industri kreatif yang belum } \\
\text { maksimal }\end{array}$ \\
\hline $\begin{array}{l}\text { OPPORTUNITIES (O) } \\
\text { 1. Pasar bebas MEA } \\
\text { 2. Kemajuan teknologi informatika } \\
\text { 3. kemajuan teknologi industri } \\
\text { 4. Kebijakan bebas VISA }\end{array}$ & $\begin{array}{l}\text { STRATEGI S-O } \\
\text { 1. Meningkatkan posisi ekonomi Kota } \\
\text { Magelang untuk menghadapi MEA. } \\
\text { (S1, S2, S3, O1) } \\
\text { 2. Mengembangkan produk sektor } \\
\text { basis dengan memanfaatkan } \\
\text { kemajuan teknologi (S4, O2, O3) } \\
\text { 3. Meningkatkan pendapatan daerah } \\
\text { dengan memanfaatkan kebijakan } \\
\text { bebas VISA }(\mathrm{S} 3, \mathrm{O} 4)\end{array}$ & $\begin{array}{l}\text { STRATEGI W-O } \\
\text { 1. Memaksimalkan realisasi investasi } \\
\text { untuk dapat berkompetisi di pasar } \\
\text { bebas MEA (W1, O1) } \\
\text { 2. Mengembangkan sektor industri } \\
\text { pengolahan dengan kemajuan } \\
\text { teknologi industri (W2, O3) } \\
\text { 3. Memaksimalkan promosi sektor } \\
\text { unggulan dan industri pengolahan } \\
\text { untuk meningkatkan eksistensi Kota } \\
\text { Magelang di pasar bebas MEA (W3, } \\
\text { O1) }\end{array}$ \\
\hline $\begin{array}{l}\text { THREATS }(\mathbf{T}) \\
\text { 1. Persaingan antar wilayah } \\
\text { 2. Bencana alam } \\
\text { 3. Pasar bebas MEA }\end{array}$ & $\begin{array}{l}\text { STRATEGI S-T } \\
\text { 1. Menciptakan keadaan yang aman } \\
\text { dan kondusif untuk meningkatkan } \\
\text { perekonomian Kota Magelang agar } \\
\text { dapat bertahan pada persaingan antar } \\
\text { daerah dan pada pasar bebas MEA } \\
(\mathrm{S} 1, \mathrm{~S} 2, \mathrm{~S} 3, \mathrm{~S} 4, \mathrm{~S} 5, \mathrm{~T} 1, \mathrm{~T} 2)\end{array}$ & $\begin{array}{l}\text { STRATEGI W-T } \\
\text { 1. Menciptakan iklim usaha yang } \\
\text { baik dan kompetitif untuk menarik } \\
\text { minat investor }(\mathrm{W} 1, \mathrm{O} 1, \mathrm{O} 2) \\
\text { 2. Mendorong pengembangan sektor } \\
\text { industri pengolahan agar dapat } \\
\text { bersaing (W2, O1) }\end{array}$ \\
\hline
\end{tabular}

Sumber: Data diolah

\section{Matriks Hasil Analisis SWOT}

\section{Strategi Strength-Opportunities (S-O)}

Strategi S-O adalah strategi yang didapat dengan menggunakan seluruh kekuatan internal yang dimiliki oleh Kota Magelang untuk mendapatkan keuntungan-keuntungan dengan memanfaatkan peluang yang ada. Beberapa strategi S-O yang dihasilkan antara lain:

a. Meningkatkan posisi ekonomi Kota

Magelang untuk menghadapi pasar bebas

MEA b. Mengembangkan produk sektor basis dengan memanfaatkan kemajuan teknologi. Kota Magelang memiliki 14 sektor basis dengan nilai $L Q>1$ yang terdiri dari sektor sekunder dan tersier sehingga perekonomian Kota Magelang dikategorikan cukup maju.

c. Meningkatkan pendapatan daerah dengan memanfaatkan kebijakan bebas VISA 


\section{Strategi Weakness-Opportunities (W-O)}

Strategi W-O merupakan strategi yang didapatkan dengan memperbaiki setiap kelemahan internal Kota Magelang yang berpotensi menghalangi datanganya keuntungankeuntungan dari peluang yang ada. Strategi W-O yang dihasilkan antara lain:

a. Memaksimalkan realisasi investasi untuk dapat berkompetisi pada pasar bebas MEA.

b. Memanfaatkan kemajuan teknologi industri untuk mengembangkan sektor industri pengolahan

c. Memaksimalkan promosi sektor unggulan dan produk industri kreatif untuk meningkatkan eksistensi Kota Magelang di pasar bebas MEA

\section{Strategi Strength-Threat (S-T)}

Strategi S-T merupakan strategi yang didapatkan dengan mengoptimalkan seluruh unsur kekuatan internal yang dimiliki Kota Magelang untuk menghadapi maupun mencegah ancaman yang datang sebaik mungkin. Adapun strategi S-T antara lain:

a. Menciptakan keadaan kondusif yang meningkatkan perekonomian Kota Magelang agar dapat bertahan pada persaingan antar daerah dan pada pasar bebas MEA.

\section{Strategi Weakness-Threat (W-T)}

Strategi W-T merupakan strategi yang diperoleh dengan mengatasi semua unsur kelemahan internal Kota Magelang yang berpotensi menyebabkan ancaman yang ada menjadi nyata atau bahkan menimbulkan ancaman baru. Strategi W-T yang dihasilkan antara lain:

a. Menciptakan iklim usaha yang baik dan kompetitif untuk menarik minat investor.

b. Mendorong pengembangan sektor industri pengolahan agar dapat bersaing dengan daerah lain.

\section{SIMPULAN}

Berdasarkan hasil analisis yang digunakan maka dapat disimpulkan:

1) Hasil analisis Tipologi Klassen yang dilakukan menunjukkan bahwa rata-rata laju pertumbuhan PDRB sebesar 5,60 persen lebih besar dibandingkan rata-rata laju pertumbuhan PDRB Jawa Tengah sebesar 5,39 persen, selain itu rata-rata pendapatan perkapita Kota Magelang sebesar Rp3.858.488, sementara Jawa tengah sebesar Rp2.144.613, sehingga pendapatan perkapita Kota Magelang lebih unggul dibandingkan Jawa Tengah maka Kota Magelang termasuk dalam Kategori daerah maju dan cepat tumbuh yang secara langsung menandakan bahwa Kota Magelang merupakan kawasan andalan di Jawa Tengah dan juga sebagai pusat pertumbuhan ekonomi daerah.

2) Hasil analisis Location Quotient (LQ) yang telah dilakukan menunjukkan bahwa terdapat 14 sektor dengan nilai LQ>1, yaitu sektor pengadaan listrik dan gas, sektor pengadaan air, pengolahan sampah, limbah dan daur ulang, sektor konstruksi, sektor perdagangan besar dan eceran; reparasi mobil dan sepeda motor, sektor transportasi dan pergudangan, sektor penyediaan akomodasi dan makan minum, sektor informasi dan komunikasi, sektor jasa keuangan dan asuransi, sektor real estate, sektor jasa perusahaan, sektor administrasi pemerintahan, pertahanan dan jaminan sosial wajib, sektor jasa pendidikan, sektor jasa kesehatan dan kegiatan sosial dan sektor jasa lainnya. Sektor-sektor tersebut merupakan sektor basis Kota Magelang yang dinilai potensial untuk dikembangkan agar dapat meningkatkan penerimaan daerah. Adapun sektor dengan nilai $L Q<1$ selain sektor pertambangan dan penggalian adalah sektor pertanian, kehutanan dan perikanan 
serta sektor industri pengolahan yang dinilai kurang potensial untuk dikembangkan sehingga dapat menggerakkan perekonomian Kota Magelang.

3) Analisis SWOT yang telah dilakukan menghasilkan strategi pengembangan kawasan andalan yaitu Meningkatkan posisi ekonomi Kota Magelang untuk dapat bersaing di pasar bebas MEA, mengembangkan produk sektor basis dengan memanfaatkan kemajuan teknologi serta memaksimalkan promosi produk sektor basis tersebut, memaksimalkan realisasi investasi dan juga menciptakan iklim usaha kondusif.

\section{DAFTAR PUSTAKA}

Arsyad Lincolin, 1999. Ekonomi Pembangunan,

Edisi 4, Cetakan Pertama, STIE YKPN, Yogyakarta.

Arsyad Lincolin, 2002. Pengntar Perencanaan

Pembangunan Ekonomi Daerah, Edisi

Kedua, BPEP, Yogyakarta.

Bappeda, 2014. Rencana Kerja Pembangunan Daerah Kota Magelang Tahun 2015, Bapedda Kota Magelang.

BPS, 2011. Kota Magelang Dalam Angka 2010, BPS Kota Magelang.

BPS, 2012. Kota Magelang Dalam Angka 2011, BPS Kota Magelang.

BPS, 2013. Kota Magelang Dalam Angka 2012, BPS Kota Magelang.

BPS, 2014. Kota Magelang Dalam Angka 2013, BPS Kota Magelang.

BPS, 2015. Kota Magelang Dalam Angka 2014, BPS Kota Magelang.

BPS, 2016. Kota Magelang Dalam Angka 2015, BPS Kota Magelang.

BPS, 2011. Jawa Tengah Dalam Angka 2010, BPS Jawa Tengah.

BPS, 2012. Jawa Tengah Dalam Angka 2011, BPS Jawa Tengah.

BPS, 2013. Jawa Tengah Dalam Angka 2012, BPS Jawa Tengah.
BPS, 2014. Jawa Tengah Dalam Angka 2013, BPS Jawa Tengah.

BPS, 2015. Jawa Tengah Dalam Angka 2014, BPS Jawa Tengah.

BPS, 2016. Jawa Tengah Dalam Angka 2015, BPS Jawa Tengah.

BPS, 2015. Produk Domestik Regional Bruto Kota Magelang Menurut lapangan Usaha 2014, BPS Kota Magelang.

BPS, 2016. Produk Domestik Regional Bruto Jawa Tengah Menurut lapangan Usaha 20112015, BPS Jawa Tengah.

BPS, 2016. Produk Domestik Regional Bruto Kota Magelang Menurut lapangan Usaha 20112015, BPS Kota Magelang.

Ghufron M, 2008. "Analisis Pembangunan Wilayah Berbasis Sektor Unggulan Kabupaten Lamongan Propinsi Jawa Timur", Skripsi, Institut Pertanian Bogor, Bogor.

Kuncoro M dan Aswandi H, 2002. “Evaluasi Penetapan Kawasan Andalan Studi Empiris Di Kalimantan Selatan 1993-1999", Jurnal Ekonomi dan Bisnis. Vol. 17, No. 1, 27-45.

Kuncoro Mudrajad, 2000. Ekonomi Pembangunan, Teori, Masalah dan Kebijakan, UPP AMP YKPN, Yogyakarta.

Robinson Tarigan, 2004. Ekonomi Regional Teori dan Aplikasi, Bumi Aksara, Jakarta.

Sabana Choliq, 2007. "Analisis Pengembangan Kota Pekalongan Sebagai Salah Satu Kawasan Andalan Di Jawa Tengah", Tesis, Universitas Diponegoro, Semarang.

Syafrizal, 1997. Pertumbuhan Ekonomi dan Ketimpangan Regional Wilayah Indonesia Bagian Barat, Prisma, Jakarta. 